\title{
ОЦЕНКА ВАЛЕОЛОГИЧЕСКИХ ЗНАНИЙ И ВАЛЕОЛОГИЧЕСКОЙ КУЛЬТУРЫ У ОБУЧАЮЩИХСЯ В СТАРШИХ КЛАССАХ НА УРОКАХ ХИМИИ
}

\author{
Костионова Д.Ю., Сиголаева Т.Е., Мишина А.В., \\ Метелкина Д.С., Пешкова А.М.
}

Тульский государственный педагогический университет им. Л.Н. Толстого, г. Тула, Российская Федерация

В статье представлены результаты полученные в ходе исследования валеологических знаний и валеологической культуры обучаюшихся старших классов общеобразовательной школь.

Ключевые слова: валеология; знания; обучаюшиеся; химия; старшие классы;; экспериментальная группа; культура; здоровье.

\section{EVALUATION OF VALEOLOGICAL VALEOLOGICAL KNOWLEDGE AND CULTURE AMONG STUDENTS IN HIGH SCHOOL CHEMISTRY LESSONS}

\author{
Kostyonova D.Yu., Sigolaeva T.E., Mishina A.V., \\ Metelkina D.S., Peshkova A.M., Turina M.Th. \\ Tula state Lev Tolstoy pedagogical University, \\ Tula, Russian Federation
}

The article presents the results obtained in the study of valeological knowledge and valeological culture of teaching older classes of secondary school.

Keywords: valueology; knowledge; learner; chemistry; high school; the experimental group; culture; health.

\section{Цель}

Изучить валеологические знания и валеологическую культуру обучающихся и установить их уровень в старших классах. 
Для определения уровня сформированности валеологических знаний были использованы адаптированные для обучающихся анкеты, а для оценки уровня воспитанности культуры обучающихся использованы следующие методики: «Индекс отношения к здоровью», «Гармоничность образа жизни школьников», «Участие школьников в здоровьесберегающих и пропагандирующих здоровый образ жизни мероприятиях», «Уровень владения школьниками культурными нормами в сфере здоровья».

Анкетирование для определения уровня сформированности валеологических знаний обучающихся старших классов в экспериментальной группе показало следующие результаты (рис. 1):

- В контрольной группе из 12 обучающихся (МБОУ ЦО «№ … .») - 41,7\% (5 обучающихся) владеют основными знаниями по валеологии, $41,7 \%$ (5) частично владеют знаниями по валеологии и $16,6 \%$ (2 обучающихся) не имеют никакого представления о валеологии.

- В экспериментальной группе из 12 обучающихся МОУ СШ «№N» - 41,7\% (5 обучающихся) владеют основными знаниями по валеологии, 33,3\% (4 обучающихся) имеют некоторое представление о валеологии и 25\% (3 обучающихся) не имеют никакого представления о валеологии.

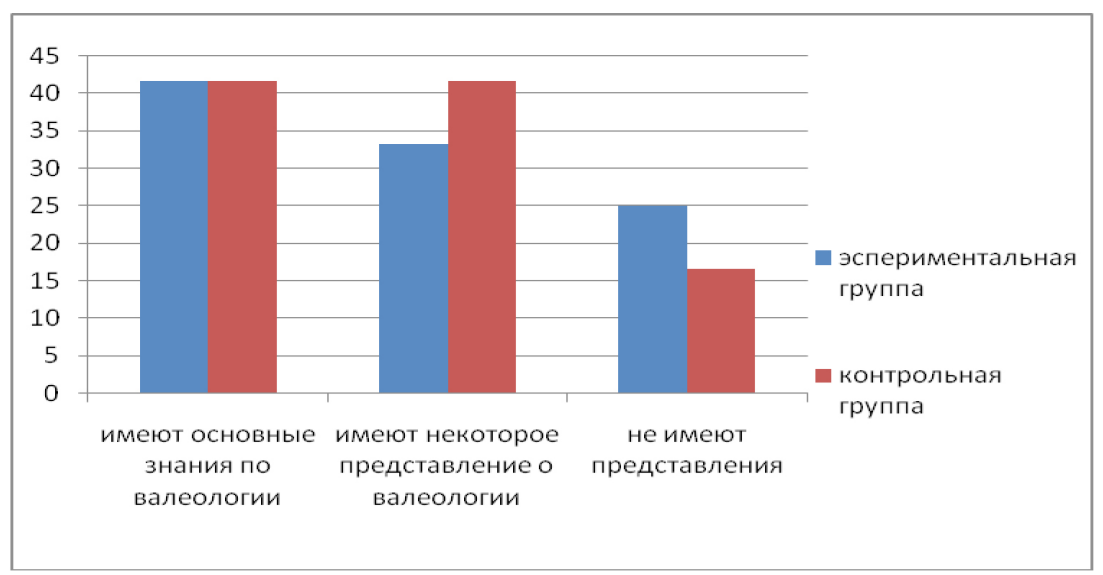

Рис. 1. Результаты оценки валеологических знаний обучающихся 
При оценке валеологической культуры учеников были получены следующие результаты (рис. 2):

На рисунке представлены результаты эксперимента проведенного в контрольной и экспериментальной группах, из которых экспериментальная группа - в которой непосредственно проводился эксперимент, а контрольная группа нужна для сравнения полученных сведений и подведению определенных умозаключений по поводу полученных знаний.
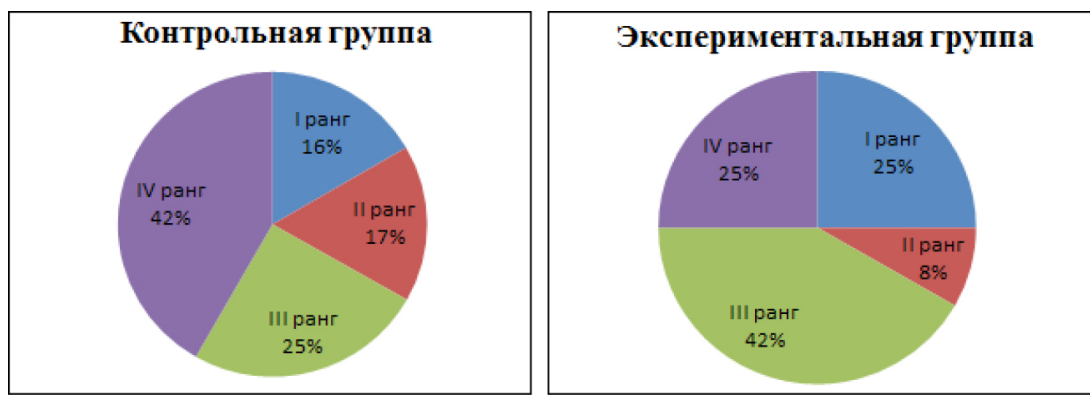

Рис. 2. Результаты анкетирования «Индекс отношения к здоровью»

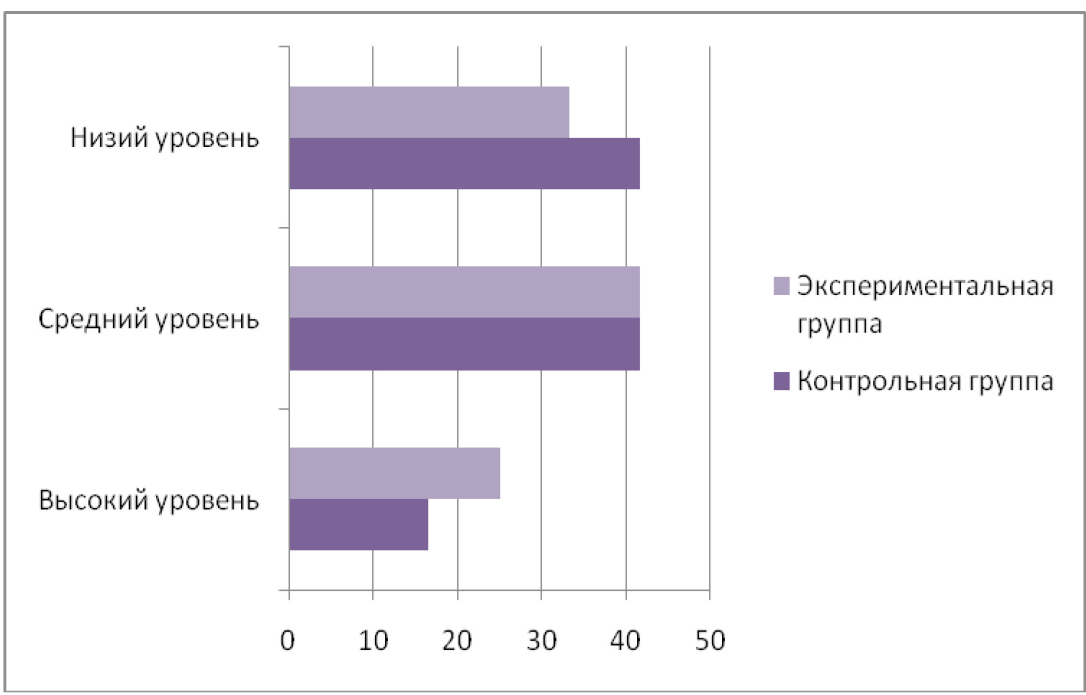

Рис. 3. Результаты оценки уровня воспитанности культуры здоровья обучающихся 
- Уровень воспитанности культуры здоровья у обучающихся старших классов в экспериментальной группе показал следующие результаты: низкий уровень у 4 учеников $(33,3 \%)$, средний уровень у $5(41,7 \%)$ и высокий уровень у 3 обучающихся (25\%);

- Уровень воспитанности в контрольной группе: низкий и средний уровень у 5 обучающихся $(41,7 \%)$, высокий уровень показали только 2 ученика (16,6\%) (рис. 3 ):

\section{Выводы}

В связи с тем, что большинство обучающихся в экспериментальной группе заинтересованы в валеологизации процесса обучения химии и имеют недостаточный уровень сформированности валеологических знаний, необходимо включить валеологические компоненты в процесс обучения химии в старших классах общеобразовательных организаций. Чем больше в школьную программу будет включаться валеология, тем безопаснее будет наша жизнь и жизнь наших детей и внуков. 